\title{
A facilitating developmental program of communication for children with developmental disorders using co-cooking activities.
}

Tsutomu Nagasaki (Jissen Women's University) Sadahito Yoshii (University of Yamanashi) Mizuho Hyodo (University of Tsukuba) Mio Amano (Jissen Women's University)

I . Purpose of this study
Recently, several studies in the brain
science have suggested that the activity
observed in the children's co-preparing
and taking foods with adults, have effects
on the activation of their prefrontal cortex
of the brain and also on their
communication development
(Kawashima,2016).
And several observational studies of
parent-child interaction on making
concentrated beverage with water showed
that parent-child interactions provides the
child with opportunities to foster abilities to
think independently and to interact with
others (Kotani,2016).

others (Kotani,2016).

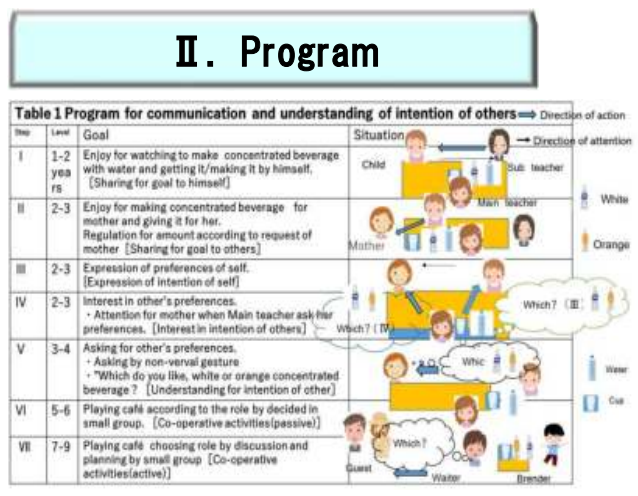

Depends on these researches, a facilitating developmental program of communication for children with developmental disorders using co-cooking by making concentrated beverage with water activities was developed. This program is consisted of seven steps. The children make

concentrated beverages for their own, for their parents and asking others for their preferences of kinds of concentrated beverage and tint of concentrated beverage.
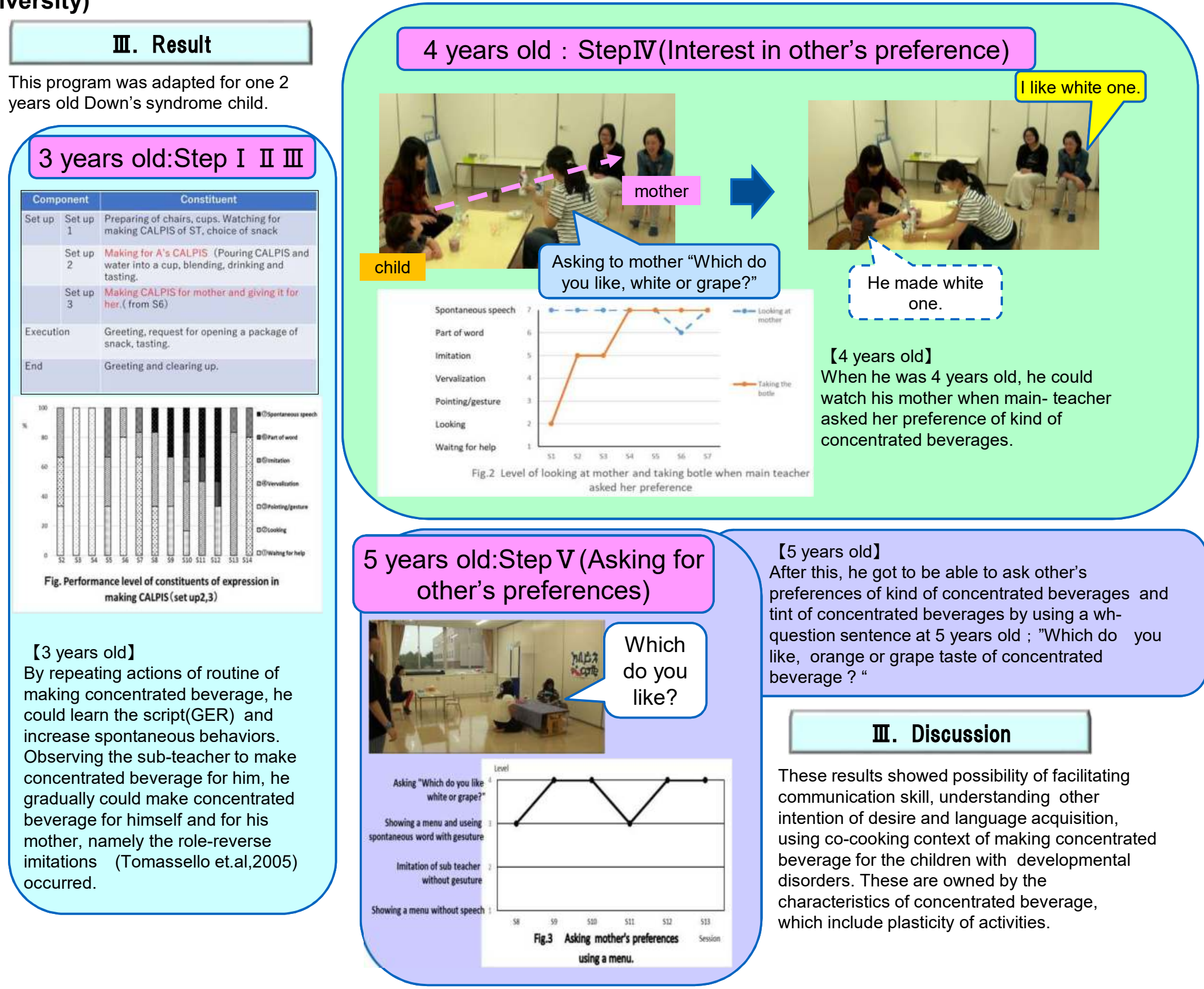

【5 years old】

After this, he got to be able to ask other's preferences of kind of concentrated beverages and tint of concentrated beverages by using a whquestion sentence at 5 years old ; "Which do you like, orange or grape taste of concentrated beverage ?"

\section{Discussion}

These results showed possibility of facilitating communication skill, understanding other intention of desire and language acquisition, using co-cooking context of making concentrated beverage for the children with developmental disorders. These are owned by the characteristics of concentrated beverage, which include plasticity of activities. 